\title{
Therapeutic Effect of Chrysin on Adenine- Induced Chronic Kidney Disease in Rats
}

\author{
Badreldin H. Alia Mohammed Al Za'abia Sirin A. Adham ${ }^{b}$ Javed Yasin ${ }^{c}$ \\ Abderrahim Nemmar ${ }^{d}$ Nicole Schupp ${ }^{\mathrm{e}}$ \\ aDepartment of Pharmacology and Clinical Pharmacy, College of Medicine and Health Sciences; \\ Sultan Qaboos University, Muscat, Oman; 'Department of Biology, College of Science, Sultan Qaboos \\ University, Muscat, Oman; 'Department of Internal Medicine, College of Medicine and Health Sciences, \\ UAE University, Al -Ain, United Arab Emirates; ${ }^{d}$ Department of Physiology, College of Medicine and \\ Health Sciences, UAE, University, Al -Ain, United Arab Emirates; eUniversitätsklinikum Düsseldorf, \\ University of Düsseldorf, Düsseldorf, Germany
}

\section{Key Words}

Rat $\cdot$ Adenine $\cdot$ Chronic kidney disease $\cdot$ Chrysin $\bullet$ Oxidative damage $\bullet$ Inflammation

\begin{abstract}
Background/Aims: To study the therapeutic effect of chrysin, a flavonoid with strong antioxidant and anti-inflammatory activities, on adenine-induced chronic kidney diseases (CKD) in rats. Methods: Chrysin, in three graded oral doses (10, 50 and $250 \mathrm{mg} / \mathrm{kg}$ ), was given for 10 consecutive days to rats after the induction of CKD by feeding them adenine $\left(0.25 \%{ }^{w / w}\right.$ for 35 days). Several plasma and urine biomarkers and tissues morphology were used the investigate chrysin effect on kidney structure and function. Results: Adenine lowered creatinine clearance and elevated the concentrations of urea, creatinine, plasma neutrophil gelatinase-associated lipocalin and urinary $N$-Acetyl-beta-D-glucosaminidase activity, and increased the concentrations of the uremic toxin indoxyl sulfate, in addition to some inflammatory cytokines. Renal histopathological markers of inflammation and fibrosis were significantly increased. Renal catalase and superoxide dismutase activities, total antioxidant capacity and reduced glutathione were all adversely affected. Most of these adenine - induced actions were moderately mitigated by chrysin, especially at the highest dose. Compared to control, chrysin did not cause any overt adverse effects on the treated rats. Conclusion: Different doses of chrysin produce variable therapeutic salutary effects in rats with CKD, and that, pending further studies, its usability as a possible therapeutic agent in human CKD should be considered.
\end{abstract}

\section{Introduction}

Chronic kidney disease (CKD) is a growing global health problem that is increasing in incidence and prevalence $[1,2]$. In both humans and animals, the pathophysiological basis 
of the disease and its complications include two main features: inflammation and oxidative stress $[3,4]$. This was evident in patients and laboratory animals with CKD in whom there are high plasma concentrations of inflammatory mediators (such as C-reactive protein, tumor necrosis factor and other cytokines) and several markers of oxidative stress $[5,6]$.

Chrysin (5, 7-dihydroxyflavone, Fig. 1), a flavonoid that is found in abundance in the flower extract of several plants as well as edible items such as mushrooms, honey and bee propolis, have several important and diverse pharmacological activities [7-10]. In rats and mice, chrysin has been shown to abate the nephrotoxicity of cisplatin and doxorubicin [11] and the hepatotoxicity of methotrexate and carbon tetrachloride [12].

Previously we studied the ameliorative effect of chrysin against adenine-induced CKD in rats, in which rats were treated with adenine to induce CKD and concomitantly given chrysin as a preventive agent [13]. Chrysin significantly and dose-dependently mitigated some of adenine biochemical and pathological toxic effects such as raised serum creatinine, increased inflammatory cytokines levels and oxidative stress markers without causing any overt adverse effect on the treated rats. However, it was not able to ameliorate significantly the adenine -induced morphological damage.

In the present work, we studied the possible therapeutic effect of chrysin on adenineinduced CKD, where chrysin was given after the end of adenine treatment (established CKD).

\section{Materials and Methods}

The studied animals, biochemical methods, Western blotanalysis, histopathology studies and statistical analysis ( $p$ values $<0.05$ considered significant) is similar to the previously published work (ameliorative effect of chrysin) [13].

The experimental design was also similar except for treatment protocol, which was as following:

Rats $(n=48)$ were randomly divided into eight equal groups and left for one week to acclimatize to their groups before treating them for 45 days as follows:

The $1^{\text {st }}$ (control) group continued to receive the powdered diet without treatment until the end of the study after 45 days.

The $2^{\text {nd }}$ group was switched to a powdered diet containing adenine $(0.25 \%$ w/win feed) for 35 days. Thereafter, adenine was stopped and rats were given normal powdered feed plus saline $(1 \mathrm{ml} / \mathrm{kg})$ for 10 days more.

The $3^{\text {rd }}, 4^{\text {th }}$ and $5^{\text {th }}$ groups were given normal powdered diet as in group one, and then given chrysin orally by gavage at doses of 10,50 and $250 \mathrm{mg} / \mathrm{kg}$, daily for 10 days, respectively.

The $6^{\text {th }}, 7^{\text {th }}$ and $8^{\text {th }}$ groups were treated as in groups 3,4 and 5 except that normal food was replaced by adenine.

\section{Results}

\section{Physiological data}

The general appearance of the rats with adenine - induced CKD was subjectively judged to be improved by chrysin treatment, especially at the highest dose $(250 \mathrm{mg} / \mathrm{kg})$. The kidneys from the control and chrysintreated rats appeared normal. However, the kidneys of adenine-treated rats were pale and with white crystals, similar to that described before [14-16]. The appearance of the kidneys of rats treated with adenine plus the three doses of chrysin were improved compared with the kidneys of rats treated with adenine alone.
Fig. 1. Chemical structure of chrysin (5,7 dihydroxy flavone).

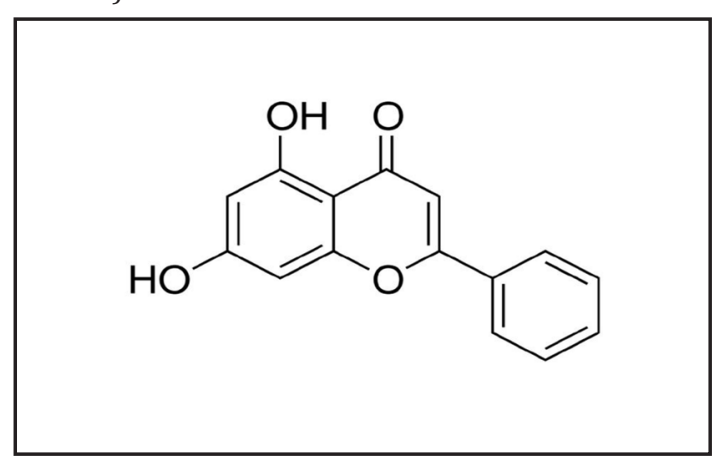


Table 1. Effect of chrysin treatment on some physiological parameters in rats with adenineinduced chronic kidney disease. Values in the tables are mean $\pm \operatorname{SEM}(n=6)$. Chronic kidney disease (CKD) was induced by the inclusion of adenine in the feed at a concentration of $0.25 \%$ $\mathrm{w} / \mathrm{w}$ for 35 days and then chrysin $(10,50$, and $250 \mathrm{mg} / \mathrm{kg}$ ) was given orally by gavage for 10 days after induction of CKD. On the last day of the treatment, the rats were placed in metabolic cages to collect urine. Values with superscripts are statistically different $p$ value a vs control; ${ }^{\text {b }}$ groups treated with chrysin alone vs. its corresponding groups treated with adenine+chrysin

\begin{tabular}{lllll}
\hline Group & $\begin{array}{l}\text { Body weight } \\
\text { change }(\%)\end{array}$ & $\begin{array}{l}\text { Relative kidney } \\
\text { weight }(\%)\end{array}$ & $\begin{array}{l}\text { Water } \\
\text { intake }(\mathrm{mL})\end{array}$ & $\begin{array}{l}\text { Urine } \\
\text { output }(\mathrm{mL})\end{array}$ \\
\hline Control & $27.4 \pm 2.7$ & $0.7 \pm 0.0$ & $17.1 \pm 1.5$ & $8.7 \pm 1.4$ \\
Adenine & $-3.8 \pm 1.2^{\mathrm{a}}$ & $2.4 \pm 0.1^{\mathrm{a}}$ & $65.8 \pm 5.5^{\mathrm{a}}$ & $52 \pm 4.1$ \\
Chrysin $(10 \mathrm{mg} / \mathrm{Kg})$ & $23.9 \pm 6.9$ & $0.7 \pm 0.1$ & $19.6 \pm 0.7$ & $11.2 \pm 1.1$ \\
Chrysin $(50 \mathrm{mg} / \mathrm{Kg})$ & $25.9 \pm 10.4$ & $0.8 \pm 0.0$ & $16.1 \pm 2.0$ & $9.5 \pm 0.6$ \\
Chrysin $(250 \mathrm{mg} / \mathrm{Kg})$ & $9.6 \pm 1.0^{\mathrm{d}}$ & $0.6 \pm 0.0$ & $15.3 \pm 1.1$ & $7.5 \pm 0.4$ \\
Chrysin $(10 \mathrm{mg} / \mathrm{Kg})+$ Adenine & $-0.4 \pm 1.1^{\mathrm{ab}}$ & $1.8 \pm 0.2^{\mathrm{ab}}$ & $42.8 \pm 1.7^{\mathrm{ab}}$ & $35.0 \pm 1.2^{\mathrm{a}}$ \\
Chrysin $(50 \mathrm{mg} / \mathrm{Kg})+$ Adenine & $1.9 \pm 0.9^{\mathrm{a}}$ & $1.7 \pm 0.1^{\mathrm{ab}}$ & $41.3 \pm 3.4^{\mathrm{ab}}$ & $34.8 \pm 1.5^{\mathrm{a}}$ \\
Chryins $(250 \mathrm{mg} / \mathrm{Kg})+$ Adenine & $-1.9 \pm 0.4^{\mathrm{ab}}$ & $1.5 \pm 0.1^{\mathrm{ab}}$ & $37.2 \pm 3.7^{\mathrm{ab}}$ & $28.8 \pm 1.2^{\mathrm{a}}$ \\
\hline
\end{tabular}
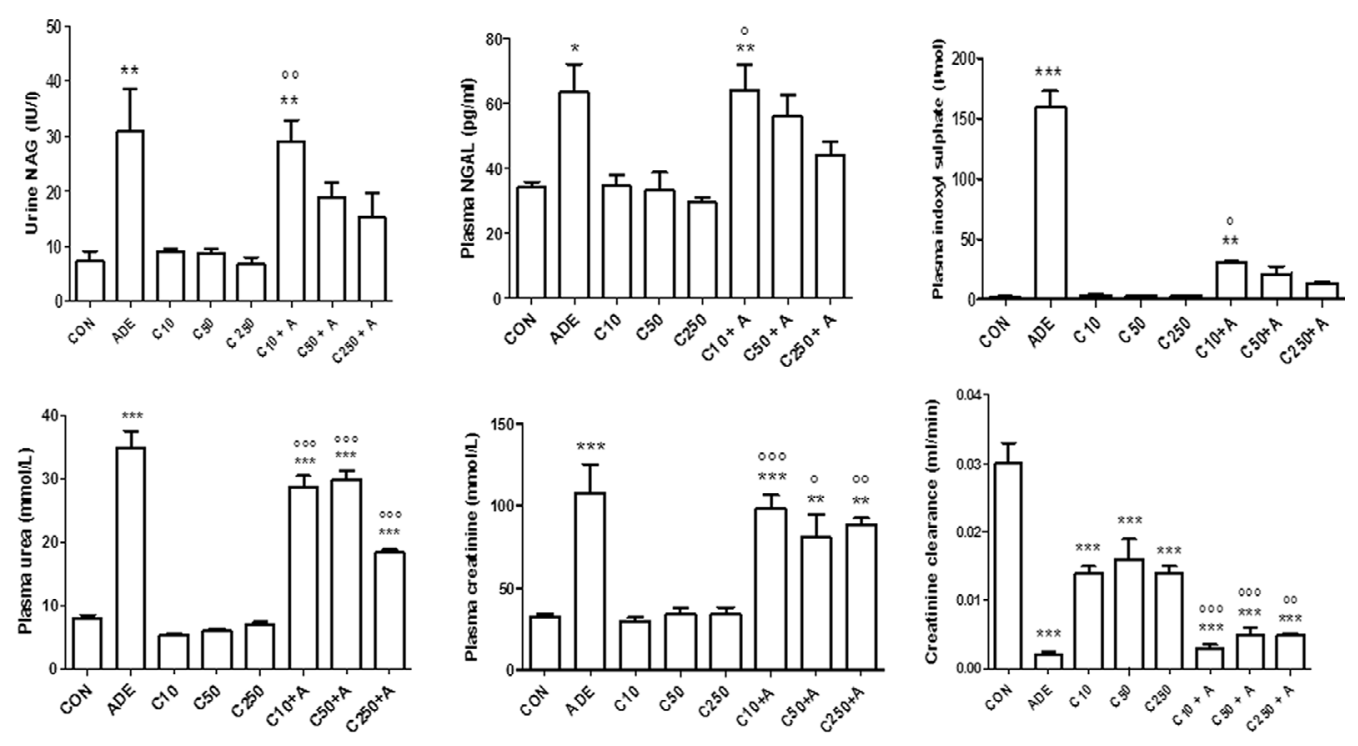

Fig. 2. Effect of chrysin treatment on creatinine clearance, and plasma concentrations of creatinine, urea, indoxyl sulfate, and 'neutrophil gelatinase-associated lipocalin (NGAL), and urinary N-acetyl- $\beta$-Dglucosaminidase (NAG) activity in control rats $(\mathrm{CON})$ or rats treated singly or concomitantly with adenine (ADE, A), chrysin (C) at doses of 10,50 or $250 \mathrm{mg} / \mathrm{kg}$. Each column and vertical bar is a mean \pm SEM $(\mathrm{n}=6)$. Different superscripts indicate significance as follows: ${ }^{*}$ denotes significance of different groups vs control group: where ${ }^{*} p \leq 0.05,{ }^{* *} p<0.001,{ }^{* * *} p<0.0001{ }^{\circ}{ }^{\circ}$ denotes significance of groups treated with chrysin alone $v s$. its corresponding groups treated with chrysin + adenine, where ${ }^{\circ} p \leq 0.05,{ }^{\circ} p<0.001$, ${ }^{\circ 00} p<0.0001$.

The physiological data of the eight groups of rats in the experiment are shown in Table 1. Adenine treatment significantly reduced the growth of rats, and increased the absolute and relative kidney weight, the water intake and urine output. Treatment with the three doses of chrysin increased the body weights of rats and did not significantly affect the water intake of rats, or their urine output. However, chrysin, given after the induction of adenine CKD mitigated the effects of adenine treatment, which were mostly dose - dependent and most prominent with the highest dose of chrysin. 

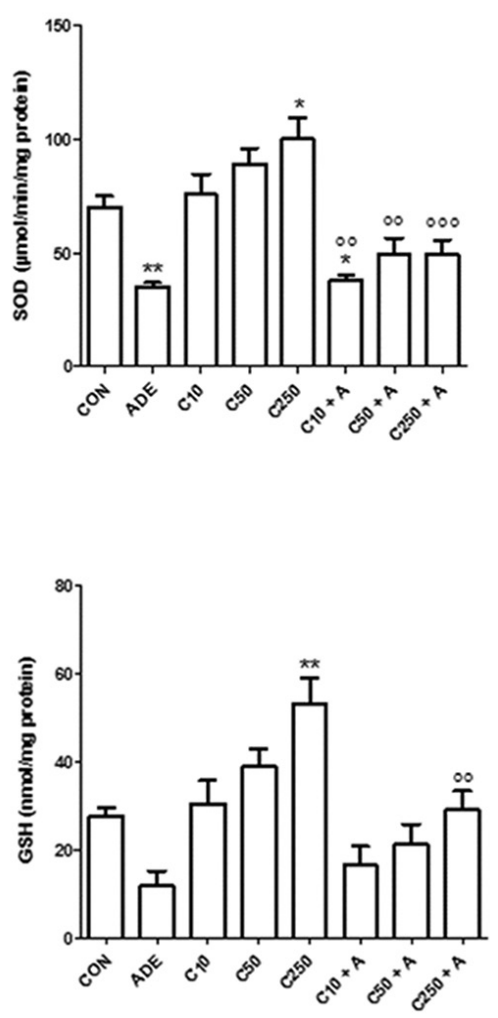
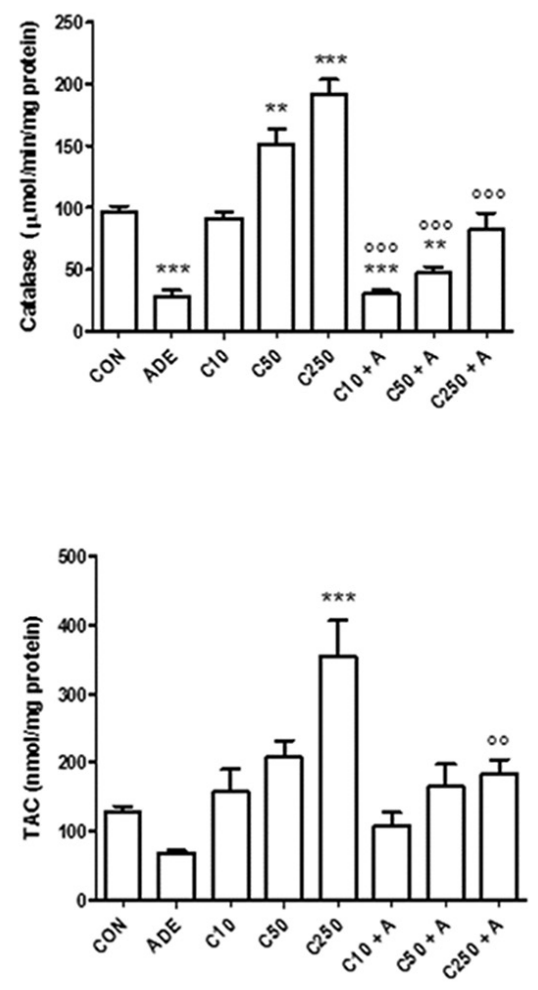

Fig. 3. Effect of chrysin treatment on renal concentration or activity of reduced glutathione (GSH), superoxide dismutase (SOD), total antioxidant capacity (TAC) and catalase in control rats (CON) or rats treated singly or concomitantly with adenine (ADE, A), chrysin (C) at doses of 10, 50 or $250 \mathrm{mg} / \mathrm{kg}$. Each column and vertical bar is a mean \pm SEM $(n=6)$. Different superscripts indicate significance as follows: ${ }^{*}$ denotes significance of different groups $v s$ control group: where ${ }^{*} p \leq 0.05,{ }^{* *} p<0.001,{ }^{* * *} p<0.0001$. $^{\circ}$ denotes significance of groups treated with chrysin alone $v s$. its corresponding groups treated with chrysin + adenine, where ${ }^{\circ} p \leq 0.05,{ }^{\circ \circ} p<0.001,{ }^{\circ o \circ} p<0.0001$.

\section{Biochemical measurements}

As shown in Fig. 2, adenine treatment increased creatinine and urea concentrations in plasma, and decreased creatinine clearance. The albumin urinary concentration in the adenine -treated rats $(29.1 \pm 3.1)$ was higher than in the control rats and rats treated with the three doses of chrysin (ranging from $4.2 \pm 0.3$ to $6.30 \pm 0.5$ ). Adenine also elevated the plasma neutrophil gelatinase-associated lipocalin (NGAL) and urinary N-acetyl-beta-Dglucosaminidase (NAG) activities, and the plasma concentration of the uremic toxin indoxyl sulfate (IS). Treatment with the three doses of chrysin alone did not significantly affect any of the above indices, and were not different from that of the controls. Administration of chrysin at the three graded doses $(10,50$ and $250 \mathrm{mg} / \mathrm{kg})$ following the end of the adenine treatment caused a dose-dependent amelioration of all above measured indices.

The effect of chrysin treatment on antioxidant indices in kidney homogenates from control rats and treated rats is shown in Fig. 3. Adenine treatment depressed superoxide dismutase (SOD) and catalase activities, glutathione (GSH) concentrations, and total antioxidant capacity. Treatment with chrysin alone at the three graded doses enhanced these indices in a dose-dependent manner. Concomitant treatment of rats with adenine and the three doses of chrysin dose-dependently abated the adenine-induced oxidative stress, especially at the highest dose of chrysin, which almost returned the anti-oxidants to what observed in control group. 
Table 2. Effect of chrysin on the activities of some enzymes in plasma rats with adenine-induced chronic kidney disease. Values in the tables are mean \pm SEM $(n=6)$. Chronic kidney disease (CKD) was induced by the inclusion of adenine in the feed at a concentration of $0.25 \% \mathrm{w} / \mathrm{w}$ for 35 days and then chrysin $(10,50$, and $250 \mathrm{mg} / \mathrm{kg}$ ) was given orally by gavage for 10 days after induction of CKD. On the last day of the treatment, rats were killed for blood collection. AST: aspartate aminotransferase, ALT: alanine aminotransferase, CK: creatinine kinase, GGT: gamma glutamyl transferase, LDH: lactate dehydrogenase. Values with superscripts are statistically different $p$ value a vs control; ${ }^{\text {b }}$ groups treated with chrysin alone vs. its corresponding groups treated with adenine+chrysin

\begin{tabular}{llllll}
\hline Enzyme & ALT (IU/L) & AST (IU/L) & CK (IU/L) & GGT (IU/L) & LDH (IU/L \\
\hline Control & $37.8 \pm 3.0$ & $75.7 \pm 9.1$ & $273.7 \pm 35.7$ & $1.1 \pm 0.2$ & $205.7 \pm 28.8$ \\
Adenine & $82.2 \pm 4.1^{\text {a }}$ & $110.8 \pm 4.9^{a}$ & $396.7 \pm 37.9^{a}$ & $4.6 \pm 0.5^{a}$ & $313.2 \pm 16.2^{\text {a }}$ \\
Chrysin $(10 \mathrm{mg} / \mathrm{Kg})$ & $52.0 \pm 3.0$ & $91.3 \pm 5.1$ & $242.8 \pm 32.8$ & $1.7 \pm 0.5$ & $192.0 \pm 28.4$ \\
Chrysin $(50 \mathrm{mg} / \mathrm{Kg})$ & $56.6 .0 \pm 4.4$ & $87.6 \pm 13.7$ a & $240.6 \pm 31.4$ & $1.7 \pm 0.4$ & $197.8 \pm 38.8$ \\
Chrysin $(250 \mathrm{mg} / \mathrm{Kg})$ & $40.2 \pm 6.9$ & $74.0 \pm 9.9$ & $203.5 \pm 31.5$ & $2.2 \pm 0.4$ & $158.0 \pm 18.0$ \\
Chrysin $(10 \mathrm{mg} / \mathrm{Kg})+$ Adenine & $73.5 \pm 9.9$ & $112.2 \pm 9.4^{\mathrm{a}}$ & $276.0 \pm 48.7$ & $2.3 \pm 0.6^{\mathrm{b}}$ & $313.2 \pm 19.1^{\mathrm{a}}$ \\
Chrysin $(50 \mathrm{mg} / \mathrm{Kg})+$ Adenine & $70.5 \pm 9.9$ & $92.6 \pm 9.3^{\mathrm{a}}$ & $231.0 \pm 18.6$ & $3.0 \pm 0.5$ & $305.7 \pm 23.2$ \\
Chryins $(250 \mathrm{mg} / \mathrm{Kg})+$ Adenine & $56.3 \pm 7.5$ & $80.8 \pm 9.3$ & $227.2 \pm 39.3$ & $3.0 \pm 0.4$ & $154.6 \pm 9.2$ \\
\hline
\end{tabular}

Fig. 4. Effect of chrysin treatment on plasma concentrations of the cytokines tumor necrosis factor alpha (TNF $\alpha)$, sclerostin, adiponectin, interleukinone beta (IL-1 $\beta$ ) and endothelin in control rats (CON) or rats treated singly or concomitantly with adenine (ADE, A), chrysin (C) at doses of 10,50 or 250 $\mathrm{mg} / \mathrm{kg}$. Each column and vertical bar is a mean \pm SEM $(n=6)$. Different superscripts indicate significance as follows: $*$ denotes significance of different groups vs control group: where ${ }^{*} p \leq$ $0.05,{ }^{* *} p<0.001,{ }^{* * *} p$ $<0.0001$. $^{\circ}$ denotes significance of groups
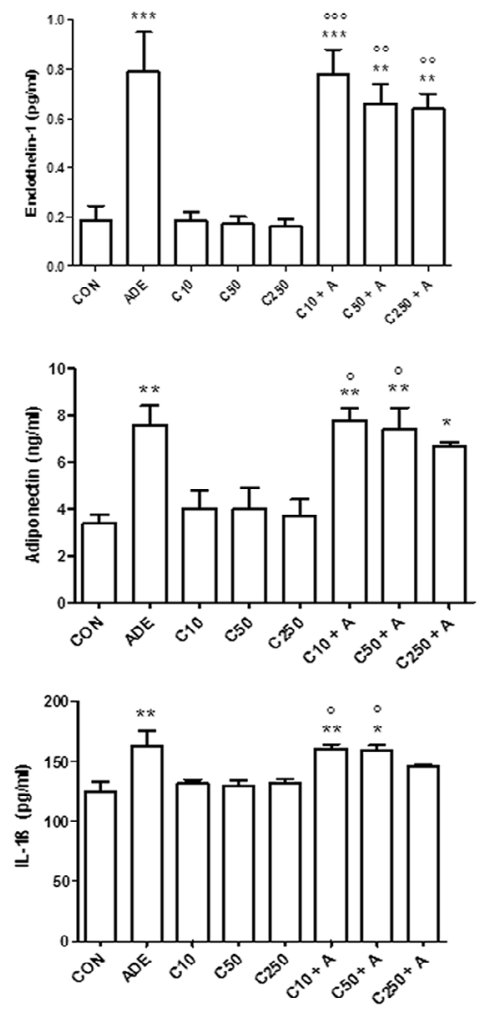
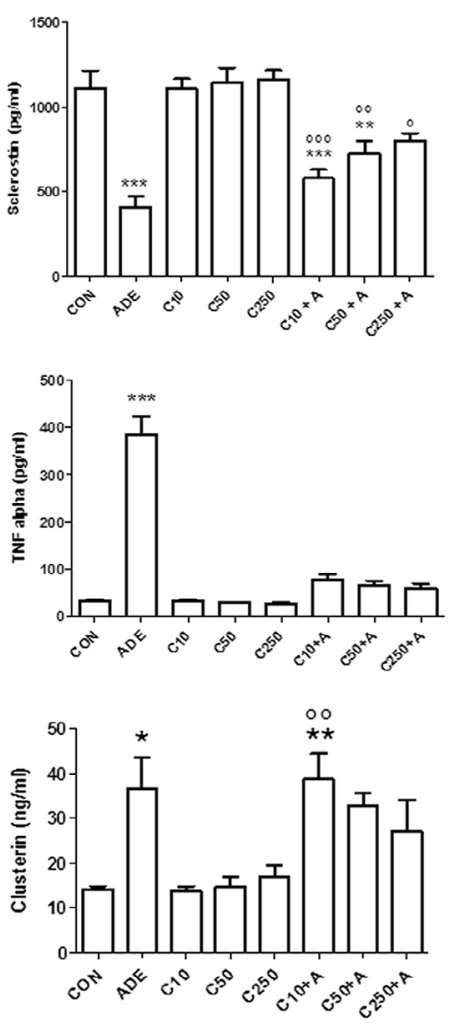

treated with chrysin alone $v s$. its corresponding groups treated with chrysin + adenine, where ${ }^{\circ} p \leq 0.05$, ${ }^{\circ 0} p<0.001,{ }^{\circ 00} p<0.0001$.

Table 2 shows the effect of the three doses of chrysin (with and without adenine co-treatment) on the activities of some enzymes in plasma. Adenine treatment caused marked increases (about 2-4 -fold) in the enzymes aspartate transaminase (AST), alanine transaminase (ALT), creatine kinase (CK), L- $\gamma$-glutamyltransferase (GGT) and lactate 


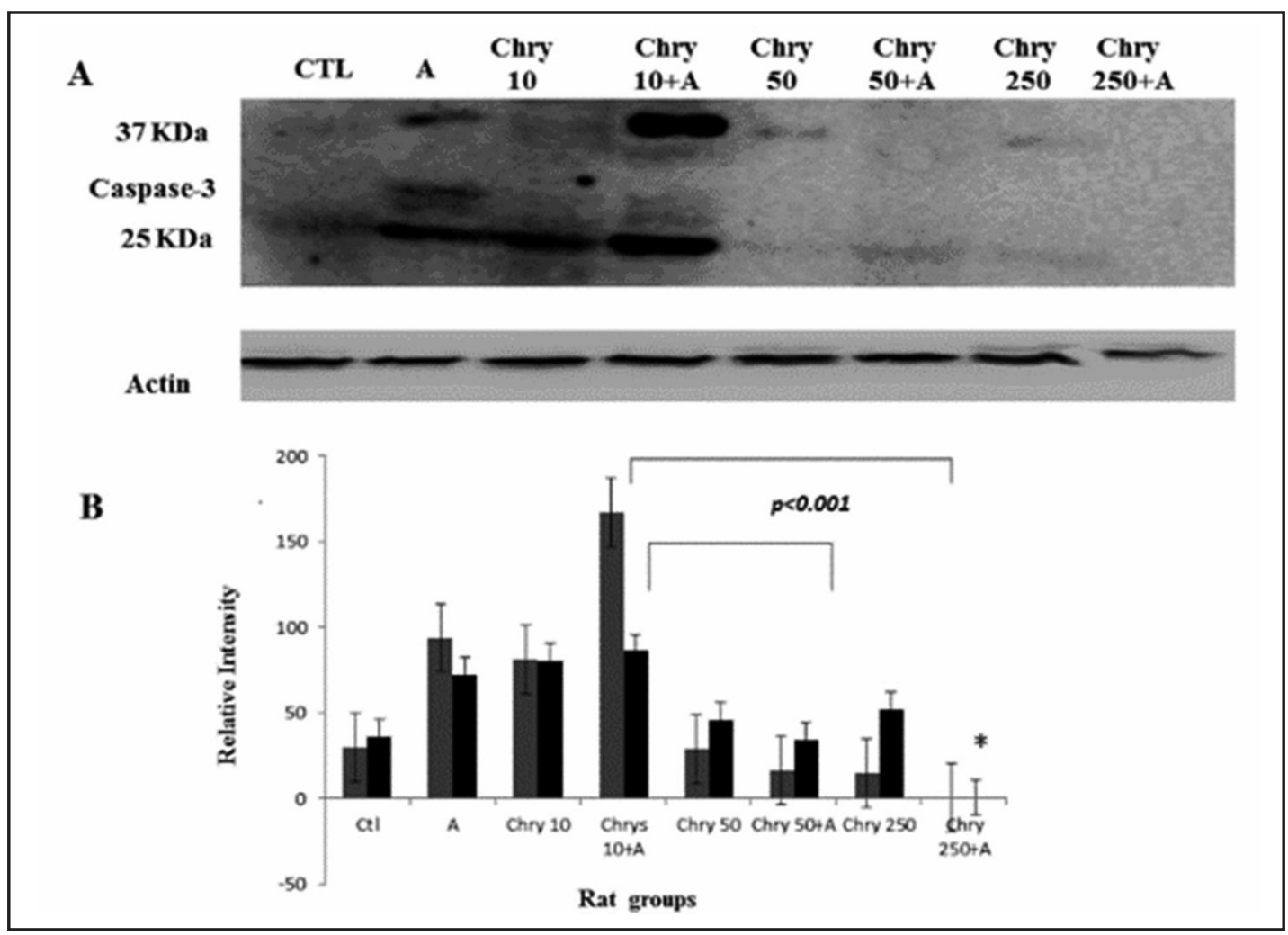

Fig. 5. (A) Western blot showing the apoptotic activity through the expression of Caspase-3 protein and the quantification of the Caspase-3 bands ( $37 \mathrm{KDa}$ and $25 \mathrm{KDa}$ ) after their normalization to the house keeping protein. Actin was calculated as the average signal of four different blots. (B) Relative intensity of cleaved and uncleaved bands. Columns and vertical bars represent means \pm SEM. CTL: control group; A: adenine treated group; Chry 10: $10 \mathrm{mg} / \mathrm{kg}$ chrysin treated group; Chry 10+A: $10 \mathrm{mg} / \mathrm{kg}$ chrysin with adenine; Chry 50: $50 \mathrm{mg} / \mathrm{kg}$ chrysin treated group; Chry 50+A: $50 \mathrm{mg} / \mathrm{kg}$ chrysin with adenine; Chry 250: $250 \mathrm{mg} / \mathrm{kg}$ chrysin treated group; Chry 250+A: $250 \mathrm{mg} / \mathrm{kg}$ chrysin with adenine.

dehydrogenase (LDH). The three doses of chrysin alone exerted no significant effect on any of the enzymatic activities. In the adenine co-treated groups, the three doses of chrysin were effective in ameliorating the action of adenine on these enzymes.

As shown in Fig. 4, adenine treatment increased the plasma concentrations of endothelin, adiponectin, TNF- $\alpha$, IL - $1 ß$, and clusterin, and decreased that of sclerostin. Treatment of rats with any of the three doses of chrysin alone did not significantly affect any of the above measured biomarkers. Co-administration of chrysin (50 and $25 \mathrm{mg} / \mathrm{kg}$ ) and adenine produced dose - dependent decrease in clusterin levels when compared to control rats and rats treated with chrysin alone. Chrysin at the highest dose $(250 \mathrm{mg} / \mathrm{kg})$ decreased IL - $1 ß$ concentrations in adenine treated rats. Chrysin, at the three doses used, also markedly decreased the TNF- $\alpha$ levels when compared with that in adenine - treated rats. The effect of chrysin treatment in the latter animals was less marked, and was only significant in case of endothelin - 1, and at the two highest dose of chrysin. Adenine decreased the concentration of sclerostin, and co- treatment with chrysin antagonized this action in a dose-dependent fashion.

\section{Molecular Analysis of Apoptosis}

As shown in Fig. 5, adenine induced the expression and cleavage of Caspase- 3 in those rats treated with adenine as a single agent as well as those treated with $10 \mathrm{mg} / \mathrm{kg}$ chrysin. However, the addition of extra chrysin $(50 \mathrm{mg} / \mathrm{kg}$ and $250 \mathrm{mg} / \mathrm{kg}$ ) inhibited the apoptosis 
Table 3. Effect of chrysin on kidney morphology in rats with adenine-induced kidney chronic disease. Values in the tables are mean \pm SEM $(n=6)$. Chronic kidney disease (CKD) was induced by the inclusion of adenine in the feed at a concentration of $0.25 \% \mathrm{w} / \mathrm{w}$ for 35 days and then chrysin $(10,50$, and $250 \mathrm{mg} / \mathrm{kg})$ was given orally by gavage for 10 days after induction of CKD. Histopathology was evaluated from kidney slices stained with hematoxylin, Masson trichrome and periodic schiff acid. Values with superscripts are statistically different p value a vs control; b vs. Chrysin ( $10 \mathrm{mg} / \mathrm{kg}$ ); c vs. Chrysin ( $50 \mathrm{mg} / \mathrm{kg})$; d vs. Chrysin (250 mg/kg); e vs. Chrysin (10 mg/kg) + Adenine; f vs. Chrysin (50 mg/kg) + Adenine

\begin{tabular}{lllll}
\hline Group & Inflammation & Fibrosis & Atrophy & Dilatation \\
\hline Control & $0.08 \pm 0.02$ & 0 & 0 & 0 \\
Adenine & $2.52 \pm 0.25^{\mathrm{a}}$ & $3.03 \pm 0.18^{\mathrm{a}}$ & $2.73 \pm 0.40^{\mathrm{a}}$ & $0.20 \pm 0.05$ \\
Chrysin $(10 \mathrm{mg} / \mathrm{Kg})$ & $0.32 \pm 0.05$ & 0 & $0.24 \pm 0.07$ & $0.07 \pm 0.04$ \\
Chrysin $(50 \mathrm{mg} / \mathrm{Kg})$ & $0.07 \pm 0.07$ & $0.17 \pm 0.04$ & $0.33 \pm 0.09$ & 0 \\
Chrysin $(250 \mathrm{mg} / \mathrm{Kg})$ & 0 & 0 & $0.47 \pm 0.13$ & 0 \\
Chrysin $(10 \mathrm{mg} / \mathrm{Kg})+$ Adenine & $2.48 \pm 0.26^{\mathrm{ab}}$ & $3.26 \pm 0.17^{\mathrm{ab}}$ & $1.35 \pm 0.28^{\mathrm{ab}}$ & $0.42 \pm 0.03^{\mathrm{ab}}$ \\
Chrysin $(50 \mathrm{mg} / \mathrm{Kg})+$ Adenine & $2.2 \pm 0.15^{\mathrm{ac}}$ & $2.06 \pm 0.19^{\text {ade }}$ & $1.43 \pm 0.15^{\mathrm{ad}}$ & $0.69 \pm 0.05^{\mathrm{ade}}$ \\
Chrysin $(250 \mathrm{mg} / \mathrm{Kg})+$ Adenine & $2.03 \pm 0.13^{\mathrm{ad}}$ & $2.40 \pm 0.27^{\text {ade }}$ & $1.58 \pm 0.16^{\mathrm{ad}}$ & $0.47 \pm 0.06^{\mathrm{adf}}$ \\
\hline
\end{tabular}

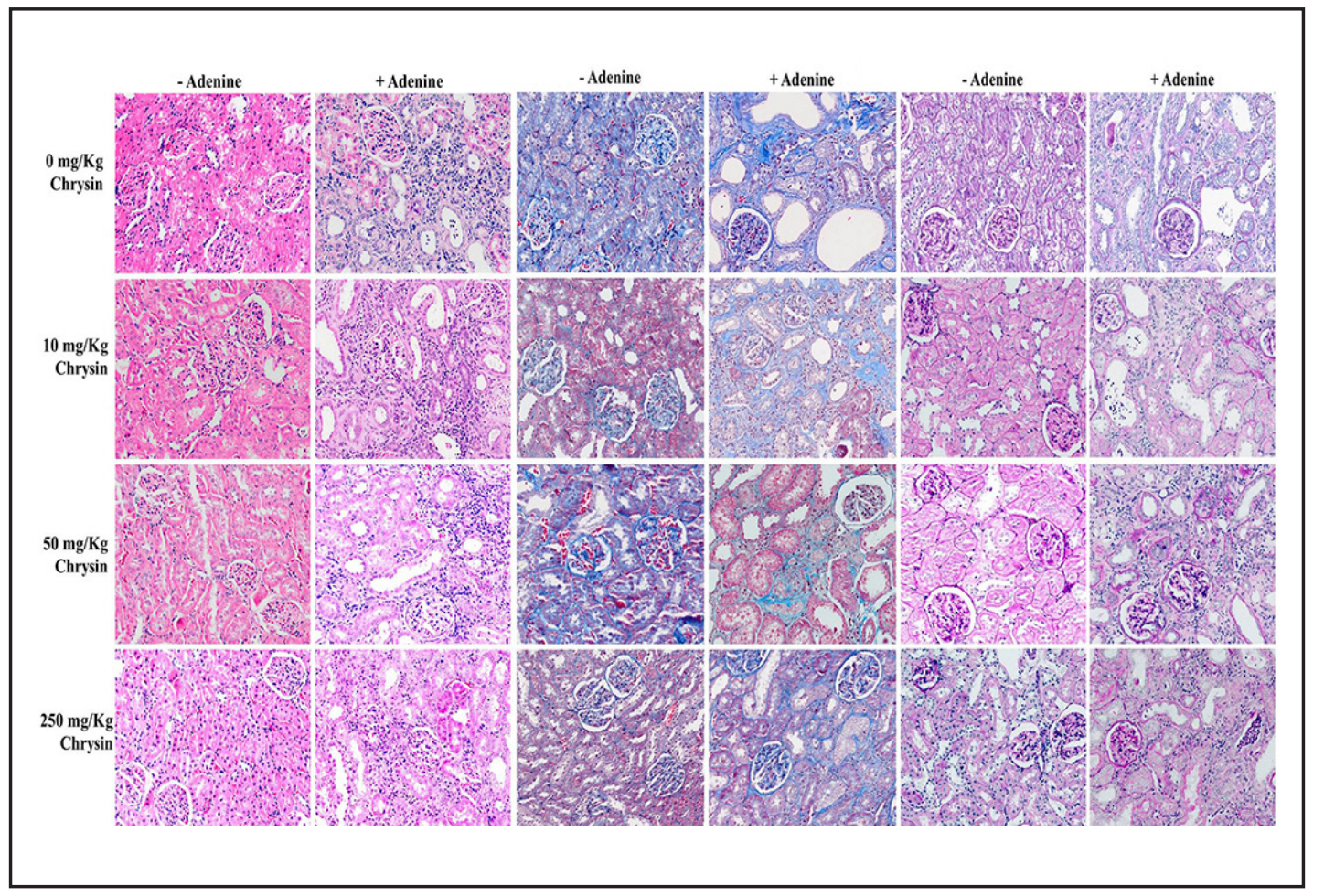

Fig. 6. Morphological changes in the kidney following treatment with chrysin at $0,10,50$ and $250 \mathrm{mg} /$ $\mathrm{Kg}$ to rats with (+ Adenine) or without (- Adenine) adenine. (A) hematoxylin and eosin stain used for the identification and semi-quantitative scoring of inflammation. (B) Masson Trichome stain used for identification and semi-quantitative scoring of fibrosis. (C) periodic acid-Schiff stain, used for the identification and semi-quantitative scoring of atrophy of the basal membrane and dilatations.

signal and brought the levels of Caspase- 3 to those levels detected in the control group. Chrysin did not show any apoptotic activity when it was used alone at the three different doses. 
Histopathology

The results of the histopathological examination of kidney sections of all the groups used (representing the degree of inflammation, fibrosis, atrophy and dilatation) are summarized in Table 3. Sections from control rats showed no signs of damage. The kidneys of adeninetreated animals showed several signs of extensive damage, inflammation, as well as fibrosis. Chrysin alone did not alter the histological appearance of the kidneys. Chrysin, given after end of adenine treatment slightly ameliorated, the pathological changes seen, mostly at the highest doses of chrysin (Fig. 6).

\section{Discussion}

Recently, we studied the preventive action of chrysin in rats given chrysin concomitantly with adenine in the feed to induce CKD, and have found that it was effective in ameliorating several of the biochemical and physiological changes induced by adenine [13]. The results of the present work have also broadly shown that chrysin produces variable therapeutic salutary effects in rats with the established adenine -induced CKD. It lessened, mostly in a dose - dependent fashion, the physiological, biochemical and histopathological changes induced by adenine.

Chrysin is known to have a strong antioxidant activity, mainly due to hydrogen atom transfer, single electron transfer or metal chelation $[17,18]$. The latter has been shown to be responsible for the amelioration of hepatic damage in diabetic mice and several other experimental organ damages $[18,19]$. The molecular basis for a connection between oxidative damage and the uremic toxin indoxyl sulfate, which have been shown to significantly rise in adenine -induced CKD [20, 21], has recently been reviewed [22].

Adenine-induced CKD was associated with a significant rise in several pro-inflammatory cytokines and a reduction in pro-antiinflammatory cytokines, as was reported before [20, $23,24]$. The three graded doses of chrysin used have not affected the levels of the measured cytokines in control rats. However, when chrysin was given after the end of the adenine treatment most of the measured inflammatory indices returned to normal, especially the TNF- $\alpha$. It is well -known that TNF- $\alpha$ is an important pro-inflammatory cytokine with well - established actions in several conditions including adenine - induced CKD [23, 25]. The inhibitory effect of chrysin on TNF- $\alpha$ suggests that this phytochemical has exerted its therapeutic effect on adenine - induced CKD, at least partly, by an anti-inflammatory action. Recently the anti-inflammatory action of chrysin has been confirmed in a mouse model of focal cerebral ischemia/ reperfusion injury by inhibiting the NF - kB signaling pathway, which is a regulator of iNOS and COX-2 expression [26].

Sclerostin, which is a novel marker of bone remodeling and vascular calcification, was depressed in rats with adenine - induced CKD. It has recently been shown that a high circulating level of this protein is associated with better survival in CKD patients undergoing dialysis $[27,28]$.

In this work, the three doses of chrysin caused only slight improvement in the morphological damage induced by adenine in the kidney. Using molecular quantification of apoptosis, chrysin did not cause any significant increase in caspase-3 levels indicating in part its lack of toxicity on the kidneys, and this was also confirmed by light histopathological examination. On the other hand, it caused only slight improvement in kidneys of rats treated with adenine.

The adenine-induced CKD model can either be reversible or irreversible depending on the duration of the treatment. Adenine fed for more than two weeks usually result in a reversible renal failure while a four weeks or a longer fed can result in a non-progressive or progressive, irreversible renal failure [29]. In this study, adenine was given for 35 days. The irreversibility of the occurred renal damage might explain the insignificant differences seen in some of the measured biomarkers and the observed histopathological changes among the chrysin treated CKD rats. 


\section{Cellular Physiology Cell Physiol Biochem 2016;38:248-257

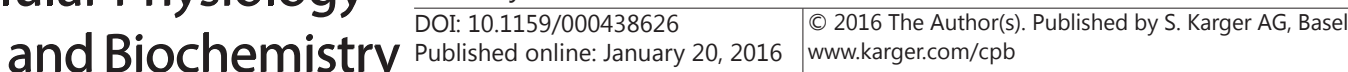 \\ Ali et al.: Chrysin in Adenine - Induced Chronic Kidney Disease}

The present results also showed an elevation of some liver enzymes in plasma of rats treated with chrysin alone. However, these were not statistically significant from control. Furthermore, chrysin ameliorated the elevation of these enzymes in adenine treated groups. Such effect of chrysin on the liver activities warrants further pharmacological and toxicological investigations.

\section{Conclusion}

This work has shown that the three graded doses of chrysin given after the induction of CDK by feeding adenine were moderately effective in abating some of the actions of adenineinduced CKD in rats. Further studies to confirm the safety and therapeutic usefulness of chrysin in this condition are warranted.

\section{Acknowledgments}

We would like to acknowledge the technical assistance of Mrs. P. Manog, Mr. M. Ashequ, and the staff of SQU Animal House. This work was financially supported by the Research Council in Oman (Grant \# RC/Med/PHAR/13/01).

\section{Disclosure Statement}

None.

\section{References}

1 Kok HM, Falke LL, Goldschmeding R, Nguyen TQ: Targeting CTGF, EGF and PDGF pathways to prevent progression of kidney disease. Nat Rev Nephro 2014;10:700-711.

2 Stack AG, Casserly LF, Cronin CJ, Chernenko T, Cullen W, Hannigan A, Saran R, Johnson H, Browne G, Ferguson JP: Prevalence and variation of Chronic Kidney Disease in the Irish Health System: initial findings from the National Kidney Disease Surveillance Programme. BMC Nephrol 2014;15:185.

3 Cantaluppi V, Quercia AD, Dellepiane S, Ferrario S, Camussi G, Biancone L: Interaction between systemic inflammation and renal tubular epithelial cells. Nephrol Dial Transplant 2014;29:2004-2011.

4 Rubattu S, Mennuni S, Testa M, Mennuni M, Pierelli G, Pagliaro B, Gabriele E, Coluccia R, Autore C, Volpe M: Pathogenesis of chronic cardiorenal syndrome: is there a role for oxidative stress? Int J Mol Sci 2013;14:23011-2332.

5 Ali BH, Al-Salam S, Al Husseni I, Kayed RR, Al-Masroori N, Al-Harthi T, Al Zaabi M, Nemmar A: Effects of Gum Arabic in rats with adenine-induced chronic renal failure. Exp Biol Med (Maywood) 2010; 235:373382.

6 Almquist T, Jacobson SH, Mobarrez F, Näsman P, Hjemdahl P: Lipid-lowering treatment and inflammatory mediators in diabetes and chronic kidney disease. Eur J Clin Invest 2014;44:276-284.

7 Ahad A, Ganai AA, Mujeeb M, Siddiqui WA: Chrysin, an anti-inflammatory molecule, abrogates renal dysfunction in type 2 diabetic rats. Toxicol Appl Pharmacol 2014;15:279:1-7.

8 Rehman MU, Ali N, Rashid S, Jain T, Nafees S, Tahir M, Khan AQ Lateef A, Khan R, Hamiza O0, Kazim S, Qamar W, Sultana S: Alleviation of hepatic injury by chrysin in cisplatin administered rats: Probable role of oxidative and inflammatory markers. Pharmacol Rep 2014;66:1050-1059.

9 Bae Y, Lee S, Kim SH: Chrysin suppresses mast cell-mediated allergic inflammation: involvement of calcium, caspase-1 and nuclear factor- $\kappa$ B. Toxicol Appl Pharmacol 2011;254:56-64.

10 Cherkaoui-Tangi K, Lachkar M, Wibo M, Morel N, Gilani AH, Lyoussi B: Pharmacological studies on hypotensive, diuretic and vasodilator activities of chrysin glucoside from Calycotome villosa in rats. Phytother Res 2008;22:356-361. 


\section{Cellular Physiology Cell Physiol Biochem 2016;38:248-257 \begin{tabular}{l|l|l} 
DOI: 10.1159/000438626 20, 2016 & $\begin{array}{l}\text { () 2016 The Author(s). Published by S. Karger AG, Basel } \\
\text { www.karger.com/cpb }\end{array}$
\end{tabular} \\ Ali et al.: Chrysin in Adenine - Induced Chronic Kidney Disease}

11 Rashid S, Ali N, Nafees S, Ahmad ST, Arjumand W, Hasan SK, Sultana S: Alleviation of doxorubicin-induced nephrotoxicity and hepatotoxicity by chrysin in Wistar rats. Toxicol Mech Methods 2013;23:337-345.

12 Anand KV, Anandhi R, Pakkiyaraj M, Geraldine P: Protective effect of chrysin on carbon tetrachloride (CCl4)-induced tissue injury in male Wistar rats. Toxicol Ind Health 2011;27:923-933.

13 Ali BH, Adham SA, Al Za'abi M, Waly MI, Yasin J, Nemmar A, Schupp N: Ameliorative effect of chrysin on adenine-induced chronic kidney disease in rats. PLoS One 2015;24:e0125285.

14 Ikeda R, Imai Y, Maruyama W, Mizoguchi K: Systemic disorders of calcium dynamics in rats with adenineinduced renal failure: implication for chronic kidney disease-related complications. Nephrology (Carlton) 2010;15:54-62.

15 Al Za'abi M, Al Busaidi M, Yasin J, Schupp N, Nemmar A, Ali BH: Development of a new model for the induction of chronic kidney disease via intraperitoneal adenine administration, and the effect of treatment with gum acacia thereon. Am J Transl Res 2015;7:28-38.

16 Ali BH, Inuwa I, Al Za'abi M, Al Bahlani S, Al Issaei H, Ramkumar A, Madanagopal T, Nemmar A, Malheiros DM, Zatz R: Renal and myocardial histopathology and morphometry in rats with adenine - induced chronic renal failure: influence of gum acacia. Cell Physiol Biochem. 2014;34:818-828.

17 Leopoldini M, Russo N, Toscano M: The molecular basis of working mechanism of natural polyphenolic antioxidants. Food Chem 2011;125:288-306.

18 Sirovina D, Orsolić N, Koncić MZ, Kovacević G, Benković V, Gregorović G: Quercetin vs chrysin: effect on liver histopathology in diabetic mice. Hum Exp Toxicol 2013;32:1058-1066.

19 Tahir M, Sultana S: Chrysin modulates ethanol metabolism in Wistar rats: a promising role against organ toxicities. Alcohol Alcohol 2011;46:383-392.

20 Ali BH, Alza'abi M, Ramkumar A, Al-Lawati I, Waly MI, Beegam S, Nemmar A, Brand S, Schupp N: The effect of activated charcoal on adenine-induced chronic renal failure in rats. Food Chem Toxicol 2014;65:321328.

21 Kobayashi T, Matsumura Y, Ozawa T, Yanai H, Iwasawa A, Kamachi T, Fujiwara K, Tanaka N, Kohno M: Exploration of novel predictive markers in rat plasma of the early stages of chronic renal failure. Anal Bioanal Chem 2014;406:1365-1376.

22 Watanabe H: Molecular mechanisms for uremic toxin-induced oxidative tissue damage via a cardiovascular-renal connection. Yakugaku Zasshi 2013;133:889-895.

23 Ali BH, Al-Salam S, Al Za'abi M, Waly MI, Ramkumar A, Beegam S, Al-Lawati I, Adham SA, Nemmar A: New model for adenine-induced chronic renal failure in mice, and the effect of gum acacia treatment thereon: comparison with rats. J Pharmacol Toxicol Methods 2013;68:384-393.

24 Ali BH, Al-Salam S, Al Za'abi M, Al Balushi KA, Ramkumar A, Waly MI, Yasin J, Adham SA. Nemmar A: Does swimming exercise affect experimental chronic kidneydisease in rats treated with gum acacia? PLoS One 2014;9:e102528.

25 García-García PM, Getino-Melián MA, Domínguez-Pimentel V, Navarro-González JF: Inflammation in diabetic kidney disease. World J Diabetes 2014;5:431-443.

26 Yao Y, Chen L, Xiao J, Wang C, Jiang W, Zhang R, Hao J: Chrysin protects against focal cerebral ischemia/ reperfusion injury in mice through attenuation of oxidative stress and inflammation. Int J Mol Sci 2014;15:20913-20926.

27 Gonçalves FL, Elias RM, Dos Reis LM, Graciolli FG, Zampieri FG, Oliveira RB, Jorgetti V, Moysés RM: Serum sclerostin is an independent predictor of mortality in hemodialysis patients. BMC Nephrol 2014;151:190.

28 Drechsler C, Evenepoel P, Vervloet MG, Wanner C, Ketteler M, Marx N, Floege J, Dekker FW, Brandenburg VM, NECOSAD Study Group: High levels of circulating sclerostin are associated with better cardiovascular survival in incident dialysis patients: results from the NECOSAD study. Nephrol Dial Transplant 2014;30:288-293.

29 Okada H, Kaneko Y, Yawata T, Uyama H, Ozono S, Motomiya Y, Hirao Y: Reversibility of adenine-induced renal failure in rats. Clin Exp Nephrol 1999;3:82-88. 